\title{
Pintura de paisaje e imagen de España: un instrumento de análisis geográfico
}

\author{
Antonio Zárate Martín *
}

DEL ESPACIO CONTEMPLADO AL ESPACIO COMPRENDIDO A TRAVÉS DE LA PINTURA DE PAISAJE

El estudio de los cuadros de paisaje como instrumento de análisis geográfico ya fue planteado en los años veinte y treinta por Sir Francis Younghusband (1920), Presidente de la Royal Geographical Society, y por Leighley (1937), al afirmar: «la clave para la comprensión de los elementos culturales del paisaje debe buscarse en métodos y resultados de la investigación del material de la producción de la creación artística». No obstante, hay que esperar a los años setenta, al socaire del resurgimiento del lado humanístico de nuestra disciplina (D. C. D. Pocock, ed. 1981) y del desarrollo de los estudios de percepción que facilitan el acceso al conocimiento de actitudes y prejuicios que intervienen en la organización del territorio, para que se renueve el interés por la pintura como objeto y herramienta de análisis espacial.

La influencia de las corrientes de pensamiento existencialista y fenomenológica sobre los fundamentos de las ciencias sociales, a partir del modelo de hombre de racionalidad limitada (SIMON, H. 1951), han impulsado la utilización de la literatura, el cine o la pintura como instrumento de análisis geográfico. Desde ámbitos muy variados, hoy, se cuestiona el estudio supuestamente objetivo del paisaje y el comportamiento pretendidamente predecible del hombre a través de fuentes como censos, datos estadísticos o planos. Cada vez se reconoce más la necesidad de utilizar

- Departamento de Geografia. UNED. 
también en la investigación geográfica fuentes expresamente subjetivas, como la literatura, el cine y la pintura, puesto que todas ellas incorporan componentes de irracionalidad que resultan imprescindibles para explicar y comprender la realidad espacial.

La complejidad del espacio impone enfoques y análisis capaces de estudiar experiencias y fenómenos, no sólo hechos y realidades. Asi, se hacen necesarios planteamientos multivariados, y cualquier tipo de aproximación a la realidad, al margen de su subjetividad, resulta válida. De este modo, el estudio de la obra de los pintores de paisaje adquiere un valor singular, sobre todo considerando que el cuadro es un elemento de conexión entre el hombre y su entorno. Como afirma A. Berque (1982), "el cuadro se configura como elemento mediador en una relación del hombre con su entorno que no es ni puramente objetiva ni completamente subjetiva, pero que integra estos dos polos superando el dualismo de lo verdadero y lo falso".

Por otra parte, como señala A. Bailly (1989), los lugares no pueden ser considerados independientemente de las personas que viven en ellos y de los investigadores que los estudian. Asi adquiere protagonismo la geografia de las representaciones, que se interroga sobre el mundo de la mente y sobre las relaciones existentes entre estas representaciones y las acciones humanas. Desde diferentes ámbitos, el análisis geográfico se ve impulsado a preguntarse por la imágenes mentales que mueven a la acción y que resultan de una mezcla de elementos reales e ideas falsas, entre otras las difundidas por los artistas. Todo ello sin olvidar, como indican diferentes modelos de percepción de la realidad, que las imágenes son resultado de la información recibida por cada individuo, de sistemas de valores propagados por la cultura y manipulados por los medios de comunicación de masas, y de desplazamientos habituales y ocasionales (GoOdNEY 1973).

En un contexto en el que lo real no se reduce a lo racional, y en el que las ciencias sociales ponen de relieve que las percepciones y las imágenes no siempre encajan con el medio "objetivo" de los técnicos, la pintura de paisaje es un instrumento privilegiado de análisis subjetivo del espacio y de conocimiento de lo que hay de irracional en los actos del hombre. Mejor que el ojo, demasiado movil, y mejor que la foto, registrador pasivo, el cuadro muestra el orden existente en una porción de territorio, si bien a través de la mente y la intencionalidad del artista (PIVETEAU 1989).

La pintura, sin otras mediaciones que nuestros filtros culturales y personales, nos ofrece una sinopsis de la organización del espacio y nos introduce en una relación interactiva con el mundo que mueve a la ima- 
ginación del geógrafo, teniendo en cuenta, como dice R. Char, que pintura y literatura pertenecen al grupo de los «lenguajes que fundan" frente al de los "lenguajes que enuncian» (PIVETEAu 1989). De este modo, la pintura de paisaje interesa al geógrafo no como obra de arte en si misma sino por lo que cuenta de la realidad, como lenguaje que capta las cosas desde la distancia y que sirve de referencia para describir el espacio real, a la vez que lo enriquece perceptualmente a través de la repetición de sus representaciones por los artistas y de la creación de estereotipos mentales por ellos mismos.

Sin embargo, la utilización del cuadro como instrumento de análisis geográfico ha de hacerse teniendo en cuenta el carácter limitado de su información y la naturaleza múltiple de su lenguaje. Por un lado, la obra de arte privilegia espacios y puntos de vista concretos mientras que ignora otros. Por otro lado, su lenguaje, que prima lo que embellece o impulsa la imagen que acrecienta el efecto buscado, varía según escuelas, movimientos y pintores. Así, se pasa de la máxima preocupación técnica por la perspectiva a partir del Renacimiento, fundamental en la representación de la realidad, a una progresiva menor observación de sus leyes y a su total abandono en el "desconstructivismo". Al mismo tiempo, se pasa por etapas y periodos en las que los pintores representan paisajes inventados, paisajes más o menos "objetivos", a menudo libres de presencia humana significante, y paisajes que traducen la vida interior del artista.

Por último, hay que destacar la importancia de la pintura, lenguaje que va más allá de la imagen, en la creación de estereotipos mentales sobre lugares y puntos de vista, y su repercusión sobre las actitudes y comportamiento de los individuos, puesto que el cuadro, como "comprensión del espacio" que es, no se disocia de la acción sobre el mismo. A través de la obra de arte, el pintor proyecta una concepción del territorio, la suya, que influye sobre la mente del espectador, modifica su observación y en consecuencia condiciona su conducta en mayor o menor grado. Recordando las palabras de P. Klee: "el arte no restituye lo visible, lo hace visible», podemos decir que la pintura enseña a ver el mundo, crea imágenes mentales que cambián la realidad, y orienta la acción.

A partir de estos presupuestos, y del interés cientifico por elementos nuevos del paisaje desde el campo de la geografia: sensaciones, colores y olores (TUAN 1979), en un afán de conocimiento empatético, abordamos la contribución de la pintura de paisaje a la imagen de España. Para ello, partimos de la obra de los pintores que hemos considerado más significativos por su proyección universal y por su influencia en la historia de la pintura española. Se trata de artistas que van desde El Greco hasta los 
grandes paisajistas de finales del siglo $x \mid x$ y principios del $x x$. Todos ellos contribuyen activamente a través de sus representaciones plásticas a la construcción de lo que hemos denominado la imagen soñada, la imagen romántica y la imagen telúrica de España, como elementos que intervienen en la configuración de una geografia de las representaciones de nuestro pais.

Los lugares y motivos representados por estos paisajes nos permiten elaborar mapas que muestran el desigual peso y valor de los distintos espacios de la geografía española en la percepción mental de país. Asi, mientras determinados escenarios se repiten insistentemente a través del tiempo, definiéndose como lugares fuertes de la imagen mental de España, otros apenas son representados. Todo ello, teniendo en cuenta que significados y valores de los lugares no son estáticos sino cambiantes en función de épocas, modas, gustos estéticos, corrientes de pensamiento y personalidad de los artistas.

\section{LA IMAGEN SOÑADA}

Surge a partir de representaciones idealizadas de la realidad, desde planteamientos de fuerte espiritualidad que desmaterializan las formas y embellecen la realidad en aras a la exaltación de determinados valores relacionados con la gloria, la fama, la religión o el poder político.

A diferencia de Francia, Holanda o Inglaterra, la pintura de paisaje en España tuvo un desarrollo esporádico durante mucho tiempo y sólo fue reconocida como género autónomo a partir de la creación de la cátedra de paisaje por la Real Academia de Bellas Artes en 1844. Sin embargo, la existencia de dibujos y grabados de paisajes difundidos por la Imprenta desde el siglo XVI, y la calidad de paisajística de algunos de nuestros grandes maestros de la pintura permiten esbozar una temprana geografía de las representaciones pictóricas que constituyen el soporte de la imagen soñada de España.

Entre los dibujos y grabados predominan las vistas de ciudades. En su mayoría responden a un afán cartográfico, como las que forman parte de la obra "Civitates orbis terrarum» (Colonia, 1576-1618), de George Braun y Franz Hogenberg, y los numerosos dibujos de ciudades y villas españolas realizados por el flamenco Anton van den Wyngaerde por encargo de Felipe II. Todas ellas resultan de interés para el análisis de elementos que definen la moforlogia de la ciudad preindustrial, su forma de ocupación del territorio y de organización productiva y social del espacio, 
Pintura de paisaje e imagen de España: un instrumento de análisis...

pero destacamos dos correspondientes a Toledo, por la importancia histórica de la ciudad y su incidencia en la imagen mental de España: una, realizada por Joris Hoefnagel, muestra la ciudad desde el Sur, destacando el Alcazar, la Catedral y San Juan de los Reyes; la otra, de Anton van den Wyngaerde, perteneciente a 1563, presenta la ciudad desde el Norte, desde la carretera de Madrid.

A lo largo del siglo xvIII, bajo la influencia de pintores franceses y desde presupuestos rousseaunianos y de exaltación del poder político, también abundaron los grabados de paisajes; entre ellos las vistas de puertos, como las realizadas por Mariano Sánchez por encargo de Carlos III, y por A. Carnicero y J. Camarón, en tiempos de Carlos IV. Ahora, muchas de estas vistas responden al deseo de dar a conocer obras públicas del momento, dentro del programa de reformas ilustradas que transmiten la imagen ideal y ordenada de un pais en contraste con el estereotipo de la «España negra» que por los mismos años contribuyen a difundir por Europa viajeros como Thomas Scott, William Lightgow, Edward Clarke o Joseph Twnsend (LLEO, V. 1984).

Desde el campo de la pintura propiamente dicha, los paisajes son escasos, ya que no se ajustaban a los gustos de la Iglesia y de la Corte, principales clientes de la producción artística en España durante siglos. Los más importantes corresponden a los de Toledo de El Greco, a los fondos de la sierra de El Guadarrama de los cuadros de Velázquez, a las vistas de ciudades realizadas por J. B. del Mazo, discipulo de Velázquez, y a los escenarios madrileños de Goya.

De todos estos paisajes, destacamos los de Toledo de El Greco, por su especial contribución al mito de una España soñada que perdura hasta nuestros dias, y por su influencia en pintores posteriores hasta hacer de la ciudad uno de los principales motivos de la pintura de paisaje.

De las vistas de Toledo de El Greco, la más antigua es la que se conserva en el "Metropolitan Museum of Art" de Nueva York. Pintado hacia 1600 , dentro de la tradición del paisaje panorámico de los artistas de los Paises Bajos, combina la representación concreta de elementos del paisaje y la reconstrucción mental según el gusto del artísta y la estética manierista.

Sobre el emplazamiento espectacular que proporciona el torno encajado del Tajo y bajo un cielo de tormenta, con una luz fantasmagórica e irreal que crea sorprendentes brillos y destellos, los edificios se estilizan y se localizan de forma diferente a la realidad. El cuadro muestra sólo la parte más oriental de la ciudad, con el alcázar dominando la altura y la torre de la Catedral a su izquierda, cuando en la realidad ésta se halla a 


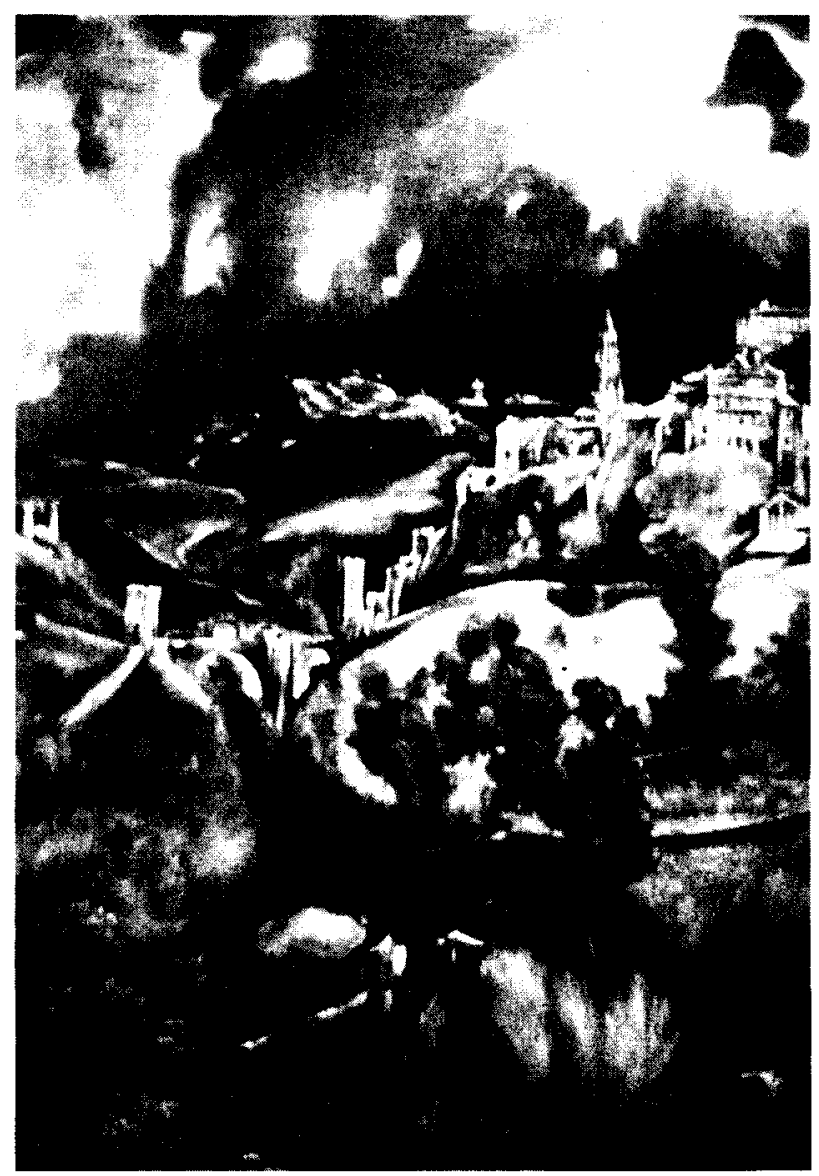

Fig. 1. Vista de Toledo. El Greco. Metropolitan Museum (Nueva York).

su derecha, e incluso, si tuvieramos en cuenta las proporciones y la composición del lienzo, debería quedar fuera del mismo.

Al pie de la colina y sobre el río se ve el puente de Alcántara, utilizado desde Roma como paso de la calzada de Zaragoza a Mérida, y a su izquierda, en alto, el castillo de San Servando, ocupando el emplazamiento de una vieja fortificación, también de origen romano, encargada de proteger el puente. En el borde inferior izquierdo del lienzo, aparece un grupo de edificios sobre una nube, que Brown y Kagan (1982) interpretan como alusión al monasterio donde se retiró San lldefonso, patrono de la ciudad. 
Pintura de paisaje e imagen de España: un instrumento de análisis...

Luces y tratamiento desmaterializado de las formas crean una atmósfera espiritual, semejante a la de los cuadros religiosos del pintor, que lleva a comentaristas como Davies a relacionarlo con la literatura espiritual contemporánea. Asi, el paisaje aparece como imagen soñada y trascendente de una realidad que facilita la comprensión empatética del territorio y genera sentimientos de topolotria hacia el medio. Por otra parte, el cuadro expresa la espiritualidad intima de un paisaje desmaterializado para el que el soporte físico es una remora, lo mismo que lo es el cuerpo para el alma en el contexto de la religiosidad española de la época.

El otro paisaje más importante de Toledo pintado por El Greco corresponde al que se conserva en el Museo de El Greco de esa misma ciudad y que Cossio (1908) relacionó con vistas venecianas del siglo xIv por la amplitud panorámica de su perspectiva. A diferencia del anterior, los edificios se localizan correctamente, con una exactitud topográfica subrayada por el plano de la ciudad que sostiene un joven, Jorge Manuel, el hijo del pintor, en la parte baja de la derecha del cuadro. Sólo el Hospital Tavera se halla desplazado de su emplazamiento real, sobre una nube en primer término y en el centro para no estorbar la vista de la puerta de Bisagra y de parte de la ciudad.

La aparición celestial de la parte superior del cuadro, la Virgen acompañada de ángeles que portan la casulla para San Ildefonso, añade carga espiritual y ensoñación a este paisaje. Las dimensiones desproporcionadas de las figuras responden a una estética orientalizante, imbuida de neoplatonismo en el tratamiento de las formas, y a un sentido metafisico según el cual los seres sobrenaturales no deben sufrir las limitaciones de la representación naturalista.

Todavia hay otros dos paisajes de Toledo pintados por el Greco, si bien como fondos escenográficos de dos temas: el de Laoconte, de hacia 1610-14, y el de la Capa de San Martin, de 1597; ambos conservados en la "National Gallery of Art" de Washington.

A través de todos estos paisajes la ciudad aparece prácticamente tal como aún la podemos ver, con sus diferentes barrios y recintos de murallas, en respuesta a la estética compartimentada y a la diferenciación funcional y social que definen la organización del espacio interior de las ciudades islámicas. En todos, la ciudad se contempla desde el norte, desde las inmediaciones del cementerio actual, consagrando uno de los puntos de vista y panorámicas que mejor definen a Toledo, coincidiendo, además, con numerosas descripciones literarias, entre ellas las del célebre geógrafo musulmán del siglo xII, El Idrisi. 


\section{LA IMAGEN ROMÁNTICA}

También la pintura contribuyó decisivamente a la elaboración y difusión de la imagen romántica de España más allá de nuestras fronteras, favorecida por el interés del romanticismo europeo hacia la cultura española por lo que encerraba de valoración de los sentimientos, de fe en los impulsos frente a la exaltación ilustrada de la razón, de evocación y pervivencia del pasado a través de monumentos y costumbres. A ello hay que añadir la admiración suscitada en el exterior hacia España por el levantamiento popular contra las tropas napoleónicas durante la Guerra de Independencia.

A parte de la influencia ambiental, recogida por Goya, pintores andaluces, como José Domínguez Becquer, Manuel Cabral y Aguado (con temas de contrabandistas, manolos, toreros y procesiones, que parecen estampas para el turismo extranjero), y artistas madrileños, como Leonardo Alenza y Eugenio Lucas (representantes de un costumbrismo crítico), la mayor incidencia en el nacimiento de la imagen romántica desde la pintura corresponde a los paisajes de Jenaro Pérez Villaamil (1807-1854). Su proyección sobre esta imagen mental se efectua desde su Cátedra de Paisaje de la Real Academia de San Fernando, creada en 1844, y desde su labor como ilustrador de revistas y libros de viajes. Entre ellos destaca la «España Artística y Monumental», repertorio gráfico de la riqueza artistica de España, comparable a la "España pintoresca y artística», de Francisco de Paula Van Halen, y a "Recuerdos y Bellezas de España», de Francisco Javier Parcerisa, editados por entonces para exaltar las «glorias de España», dentro del fuerte sentimiento patriótico derivado del renacer nacionalista que acompañó al romanticismo.

A partir de presupuestos estéticos inspirados en su amistad personal con el escocés David Roberts, que también ofrece una de las más bellas y tempranas visiones de la España romántica a través de sus litografias, Pérez Villaamil dio el impulso definitivo a la pintura de paisaje en nuestro pais. Su éxito se vio además favorecido por la adecuación de este género a los gustos de la burguesia, que ahora sustituye a la Iglesia y a la Realeza en el mecenazgo del arte y se interesa por lo cotidiano, lo popular y las bellezas de España, sobre todo después de su enriquecimiento a raiz de la desamortización de Mendizabal.

Óleos, acuarelas y dibujos de Pérez Villaamil representan vistas urbanas y exteriores e interiores arquitectónicos, generalmente medievales como corresponde a la revalorización de la Edad Media por el Romanticismo. La mayoria de sus vistas y paisajes son representaciones concretas de la realidad, pero con una tendencia al alargamiento y a la despro- 
porción que buscan la idealización de las formas, dentro de ambientes fantaseados que acentúan el clima romántico. No obstante, también pinta paisajes totalmente fantásticos o reconstruidos, combinando elementos reales de diferentes monumentos y lugares.

Por otra parte, Villaamil introduce en sus paisajes figuras populares con aire costumbrista y personajes históricos que hacen de ellos una estampa viva y testimonial de su tiempo. Aldeanos gallegos y asturianos, arrieros, soldados, vendedoras, personajes populares de las calles de Toledo y de la feria de San Isidro de Madrid, ajusticiados y bandoleros, dan la crónica social y variada de una España provinciana, pintoresca, pueblerina, diversa y de gran riqueza artística. Todo ello con un colorido cálido, brillante, de tonos dorados y atmósfera vaporosa, que aumenta el ambiente de ensoñación y de misterio caracteristico de la estética romántica.

El resultado de todo ello es una visión idealizada de España y de su historia, que se identifica con la imagen que por aquellos mismos años proyecta la literatura de viajes. A partir de Villaamil, se ponen de moda y aparecen en todas las revistas ilustradas del pais los grabados de monumentos y lugares históricos de la península, recogidos con toda suerte de detalles arquitectónicos, con criterio casi arqueológico.

\section{LA IMAGEN TELÚRICA}

La reacción al mundo ideal e imaginado del romanticismo desde el naturalismo y el positivismo, representada en la pintura de paisaje por Haës y sus discípulos, impulsó el nacimiento de una imagen colectiva de España más auténtica y profunda que la anterior.

A partir de Carlos de Häes (1826-1898), belga nacionalizado español, que formó a generaciones de artistas desde la Cátedra de paisaje de la Real Academia de San Fernando, se impone el paisaje realista en España; se abandona la composición imaginativa y se representan paisajes tomados del natural. El arte se concibe como "verdad", en palabras del propio Häes, como preocupación por el conocimiento directo y profundo de la naturaleza; todo ello bajo la influencia de los pintores holandeses y paisajistas franceses, y del cientifismo positivista, que impulsa a los pintores a representar geológica y botánicamente el territorio.

No obstante, la herencia romántica no desaparece y en el realismonaturalismo de Häes y de sus discípulos, perviven actitudes y conceptos derivados del romanticismo al que decian enfrentarse. Asi, se valora la 


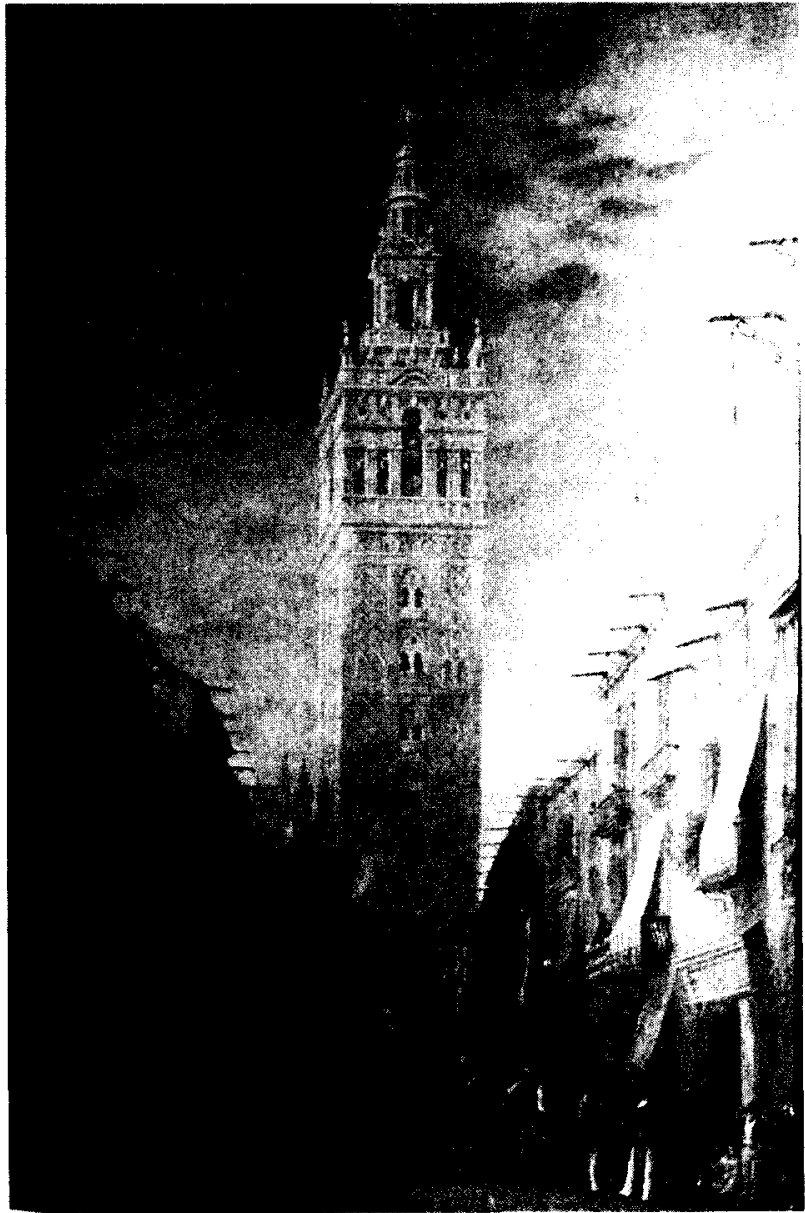

Fig. 2. La Giralda desde la calle de La Borcigueneria. Sevilla. J. Pérez Villaamil.

sensibilidad subjetiva y se considera el paisaje como expresión de sentimientos, según concepto acuñado por J. J, Rousseau. De este modo la pintura se aleja de una simple imitación de la naturaleza que se identifica entonces con la naciente fotografia.

Por esa misma carga romántica, Häes prefiere los paisajes montañosos del Norte, sobre todo de los Picos de Europa, envueltos en vaporosidad, donde la naturaleza se muestra con una dimensión misteriosa, gigantesca y sombría que se sitúa por encima del hombre, y cuando pinta la meseta castellana, lo hace a través de rincones arbolados de la Sierra 
madrileña y de parajes húmedos de las orillas del Manzanares, que constituyen lo menos característicos de ella.

Desde el punto de vista de su aportación a la imagen telúrica, Häes rompe con la visión romántica de nacionalismo arcaizante y negativo proyectada por Villaamil en base a un falso respecto por la tradición; incorpora los paisajes naturales de Castilla y, sobre todo, descubre la alta montaña española como tema paisajístico, sintonizando con lo que Martínez de Pisón (1984) denomina ciclo alpino.

Sus principales discípulos, Jaime Morera, Agustin Lhardy, Aureliano de Beruete y Darío de Regoyos, avanzan en las vias abiertas al paisaje

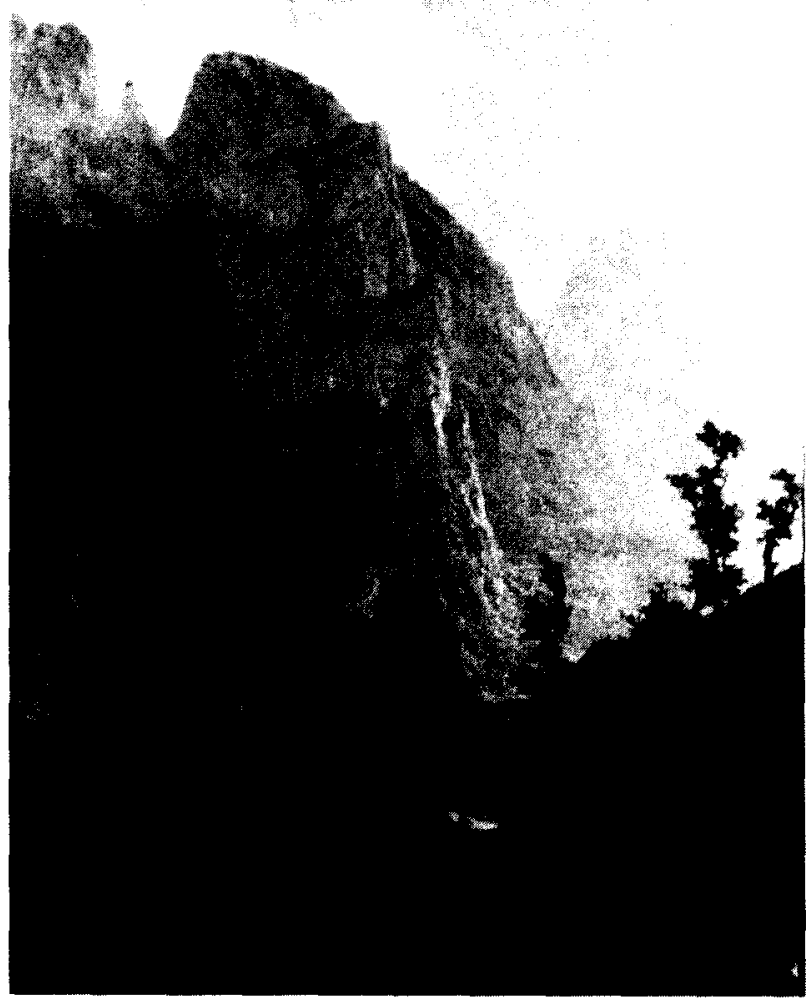

Fig. 3. Los Picos de Europa. Carlos Häes. 
por Häes, enriquecen los escenarios pictóricos y profundizan en la búsqueda de un verdadero paisaje nacional desde un proceso de renovación intelectual que arranca del Krausismo y de la Institución Libre de Enseñanza. Ahora los artistas se lanzan a plasmar en sus cuadros, bajo presupuestos positivistas, los lugares que descubren los naturalistas y que estudian los geólogos. El paisaje se convierte en algo materialmente experimentable, en expresión de nuestra historia y en espacio de proyección ética y estética (GINER DE LOS RIOS 1915).

Con Aureliano de Beruete (1845-1912), estrechamente vinculado a la Institución Libre de Enseñanza, los paisaje toledanos de El Greco, los fondos serranos de Velázquez y los escenarios madrileños de Goya, adquieren renovado protagonismo, pero ahora desde un afán por profundizar en la esencia de nuestro pais, asumiendo la realidad de sus paisajes, sus tradiciones y floklore, y desde un conocimiento detallado del terreno. Juegos de luces del paisaje, tonos amoratados y violáceos de sus cuadros representan la naturaleza de los suelos y muestran la estratigrafia del terreno, con precisión semejante a las descripciones literarias de institucionistas y escritores de la generación del noventa y ocho (PENA, C. 1983).

La sierra de Guadarrama, como "espina dorsal del pais" que simbo-

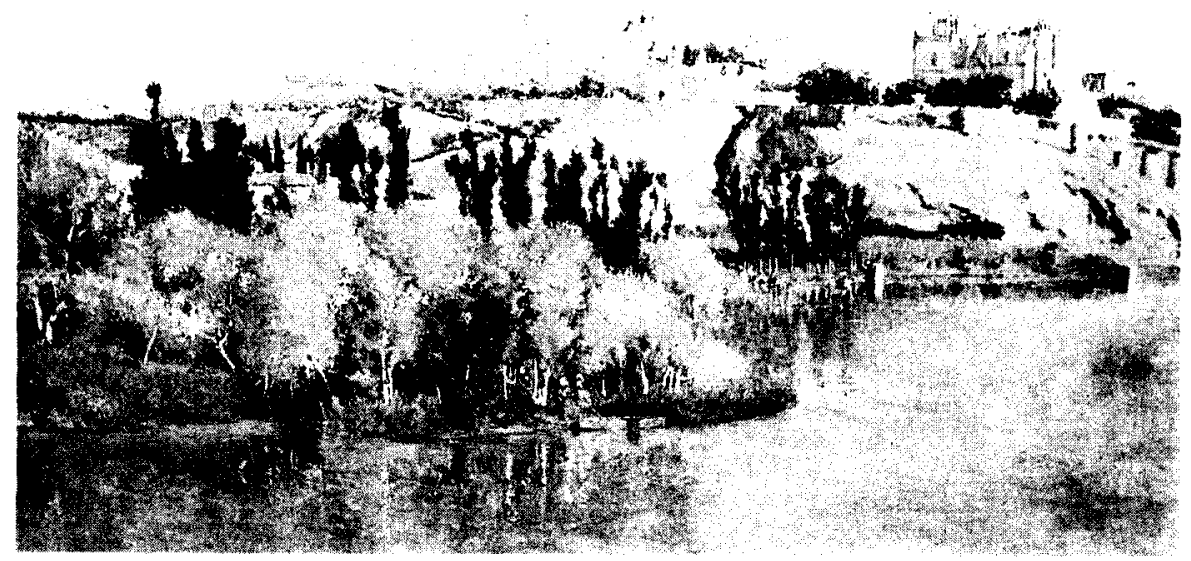

Fig. 4. Vista de Toledo desde Los Cigarrales. Aureliano de Beruete. 
Pintura de paisaje e imagen de España: un instrumento de análisis...

liza la España más profunda; la imagen melancólica de las ciudades castellanas vistas desde la afueras, sobre todo Toledo y Madrid, y las Ilanuras de la meseta, casi siempre con el contrapunto serrano del Guadarrama, son los motivos pictóricos más representados por Beruete y Lhardy, y los pilares de la imagen telúrica de España que, a lo largo de nuestro siglo, prolongan pintores de la Escuela de Vallecas, como Benjamin Palencia, Joaquín Vaquero Palacios o Rafael Zabeleta.

A esa imagen se añade también la nota tremendista que incorporan los paisajes de Dario de Regoyos (1857-1913) a través de las tonalidades ásperas de su paleta, de su libertad en la utilización del color, de su gusto por lo extraordinario, dramático y profundo, y de su labor como ilustrador del libro "La España Negra» de Verhaeren, con escenas simbolistas o próximas al expresionismo.

Los paisajes castellanos, extremeños, andaluces y, sobre todo, del País Vasco de Dario de Regoyos, en los que no faltan escenas urbanas, muestran una España provinciana, silenciosa y sombria, envuelta en un halo de tristeza que se hace siempre presente en el alma española, y del que no escapan las danzas y las fiestas, particularmente las corridas de toros.

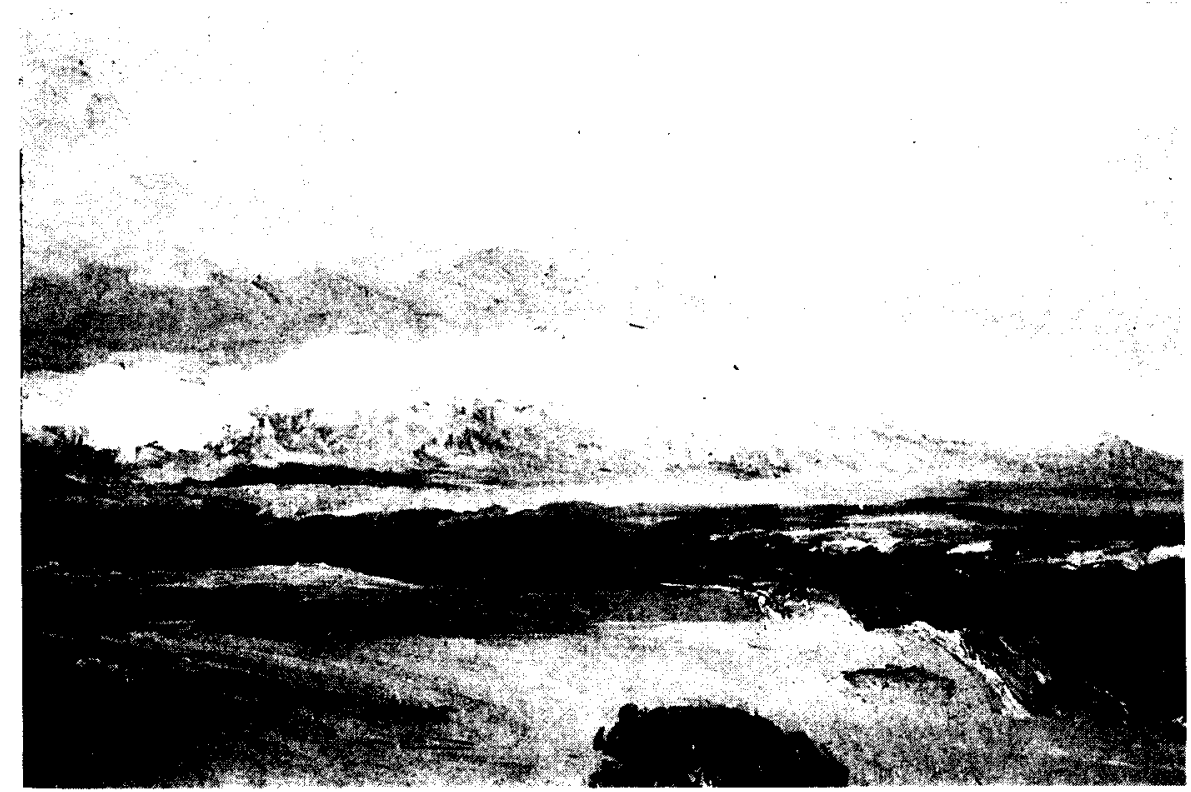

Fig. 5. Vista de la Sierra de Guadarrama. Aureliano de Beruete. 


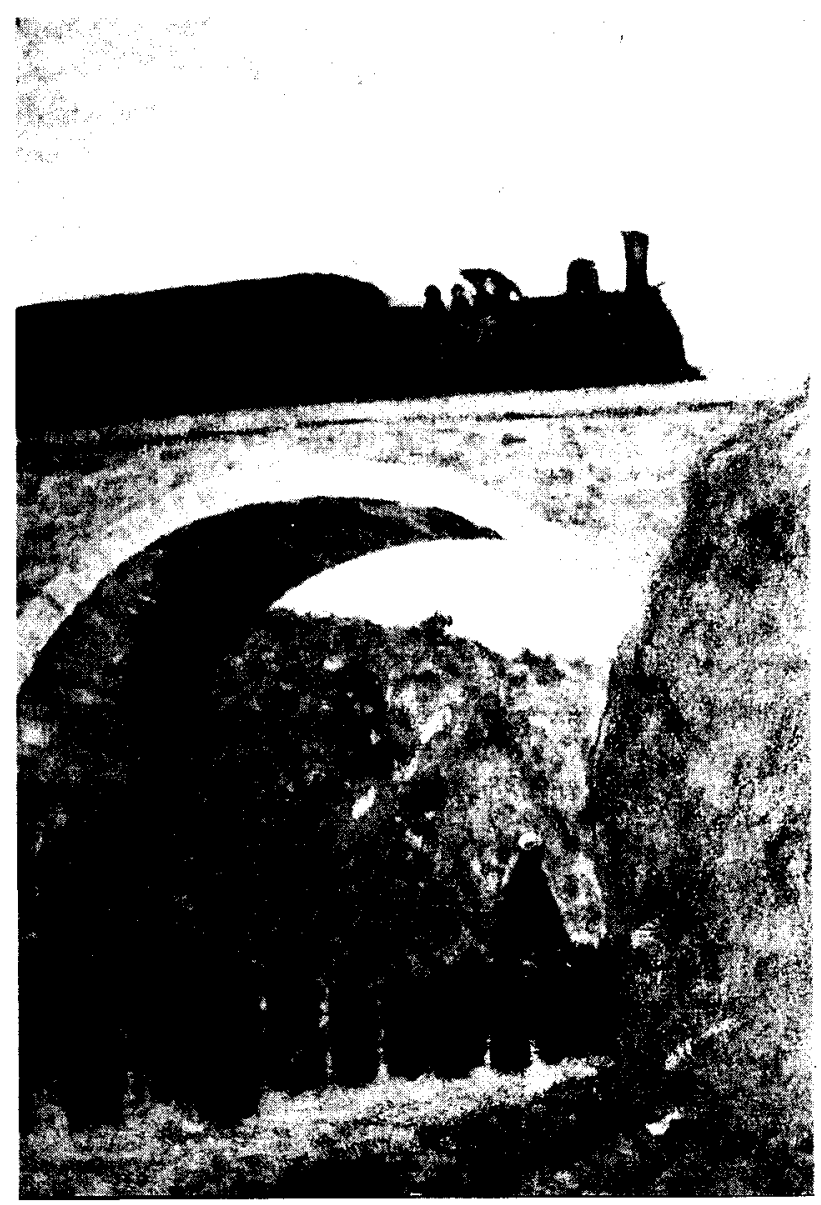

Fig. 6. Viernes Santo en Castilla. Dario de Regoyos.

\section{UN ESPACIO DESIGUALMENTE PERCIBIDO}

Del análisis pormenarizado del catálogo de las obras de los pintores de paisaje comentados antes, se desprende el desigual peso que tienen los espacios representados por ellos en la imagen mental de España, y los cambios de significado que han experimentado algunos de esos lugares en una geografía de las representaciones.

En primer lugar, destaca la fuerte incidencia en la configuración mental del pais que tienen las vistas pormenarizadas de monumentos y las 
Pintura de paisaje e imagen de España: un instrumento de análisis...

panorámicas urbanas. Las primeras como auténticos hitos simbólicos y referenciales con relación a espacios urbanos y a un tiempo histórico que se reivindica desde el Romanticismo. Las segundas, contempladas sobre todo desde el campo, en la más pura tradición de la pintura clásica y como reflejo de una sociedad española tardiamente industrializada. En cualquier caso se trata de representaciones que recogen la herencia de un pasado en el que las ciudades eran lugares de contenido simbólicos y sagrados, con una morfología cargada de significaciones (BAILLY 1978), y un presente en el que las ciudades se configuran ante todo como espacios de reproducción de la sociedad que los utiliza a diario. Además, hay que tener en cuenta que las urbes han sido siempre objeto privilegiado de tratamiento por parte de pintores y escritores, por ser escenario de la historia y marco de una realidad social, económica y política especialmente compleja.

Entre los espacios más representados figuran las ciudades castellanas, seguidas de las ciudades andaluzas y, muy de lejos, lugares del Pais Vasco, Galicia y Cataluña.

La imagen de Toledo sobresale ampliamente entre todos esos espacios, como se pone de manifiesto en los mapas que presentamos, debido a su número de representaciones y a la fuerza de su paisaje a través de El Greco, dibujos y grabados desde el Renacimiento al Romanticismo, y discipulos de Häes, sobre todo Beruete. Esa fuerza pictórica se basa en la espectacularidad de su emplazamiento, en su riqueza monumental en relación con su pasado histórico y en la carga de valores simbólicos relacionados con presupuestos institucionistas y noventayochista. Todo ello en contraste con una situación de deterioro y abandono en que la ciudad se encontraba a finales del siglo xIx.

Ya los viajeros ilustrados, como Silhouette, Caimo, Richard Twiss, Jean Peyron o Joseph Townsend, valoraron tempranamente la riqueza artistica y monumental de Toledo, contribuyendo a crear su imagen temprana como ciudad museo, pero fueron los viajeros y pintores románticos del siglo xIX los que difundieron este estereotipo mental por el mundo entero, ahora sobre la imagen orientalista y pintoresca que es la que todavía hoy mejor define a esta ciudad. La Catedral, San Juan de los Reyes e iglesias mudéjares son los monumentos más representados por dibujantes y pintores románticos.

Por otro lado, el realismo espiritualizado de finales de siglo convirtió a Toledo en protagonista de la pintura y de la literatura de aquellos años. Las vistas de la ciudad y sus alrededores son frecuente motivo pictórico de Morera y uno de los temas más representados por Beruete, en una combinación de ambiente soñado y nivel metafísico. Al igual que en la 


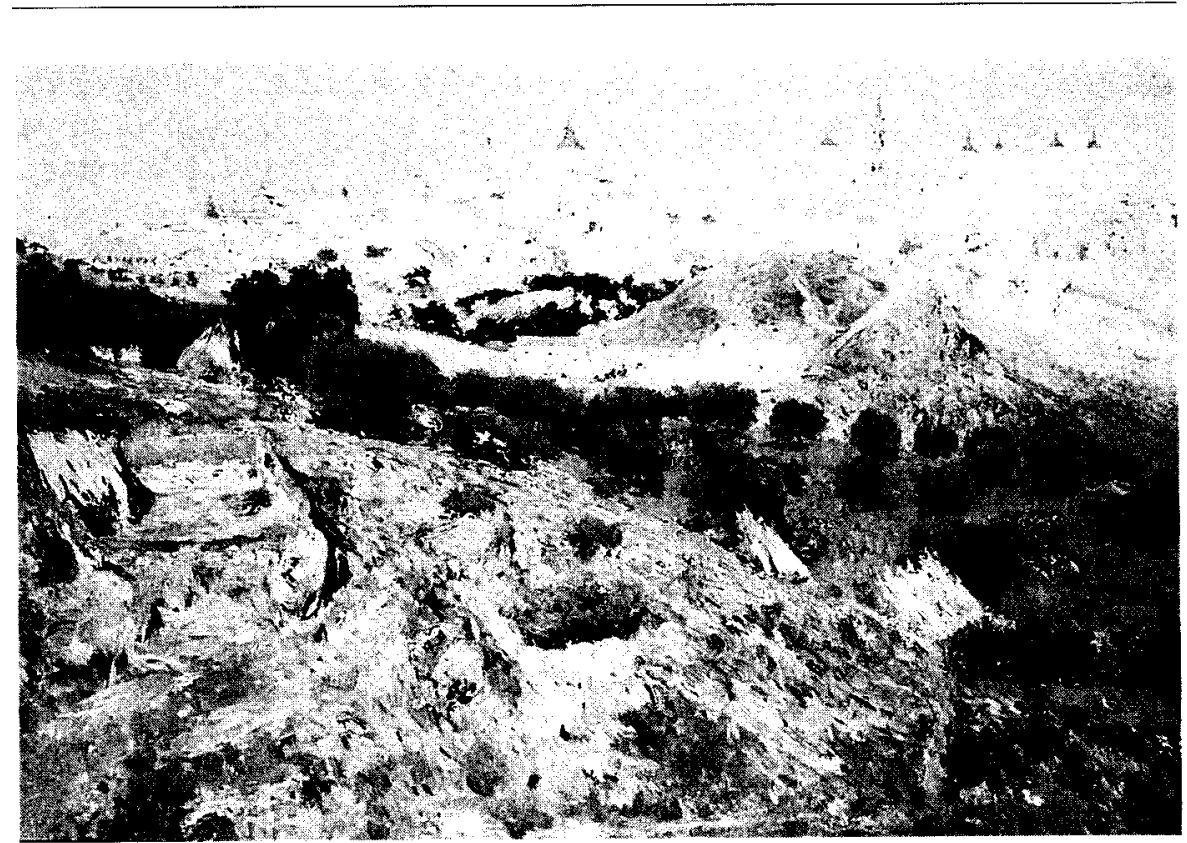

Fig. 7. Vista de Toledo desde Los Cigarrales. Aureliano de Beruete.

literatura de Pío Baroja, Galdós o Azorin, Toledo aparece en estos paisajes como evocación sentimental de la España más profunda y vínculo de unión con la estética de los grandes maestros de la pintura española. En definitiva, pintores e intelectuales del momento presentan a Toledo con un significado mitico, como "ciudad muerta" que simboliza el antiguo imperio y su decadencia (HINTERHAUSER 1980).

Madrid es la ciudad que sigue en importancia a Toledo en las obras de los pintores de paisaje seleccionados. Su papel de capital del Estado ha propiciado la representación pictórica de sus monumentos y espacios interiores por los artistas románticos, a modo de hitos urbanos, nodos y bordes en la terminologia de Lynch (1961), y la proliferación de panorámicas más o menos amplias, frecuentemente desde los arrabales, por los paisajistas del finales del $x \mid x$ y de principios de nuestro siglo.

La obra de Villaamil referida a Madrid permite dibujar una verdadera geografía urbana a través de monumentos (Palacio Real, Palacio de los Duques de Osuna, Iglesia de San Andrés, Capilla del Obispo), plazas (Puerta del Sol, Fuentecilla, Cabestreros, puerta de Atocha), calles (Toledo, los Estudios, San Pedro, Cuesta de los Ciegos), y panorámicas de la ciudad desde el otro lado del puente de Toledo, desde la Virgen del Puerto y desde la Casa de Campo. En ellas, destacan el Manzanares y 
Pintura de paisaje e imagen de España: un instrumento de análisis...

los hitos más significativos de la ciudad, el Palacio Real, San Francisco el Grande y Puerta de Toledo, a semejanza de los paisajes goyescos de Madrid desde la pradera de San Isidro.

Häes y sus discípulos, Beruete, Morera y Lhardy, ofrecen otra visión urbana: las orillas del Manzanares, con el frente de terraza fluvial sobre la que se asienta el Palacio de Oriente, desmontes solitarios y entornos suburbanos que constituyen ambientes literarios de los novelistas del 98. La mayoria de estos paisajes son panorámica de un Madrid provinciano en el que empieza a dibujarse alguna chimenea de su primera y timida industrialización. Los más numerosos corresponden a Beruete, uno de los paisajistas por excelencia de Madrid. Entre sus composiciones, proliferan las vistas de las orillas del Manzanares y de los entornos urbanos, casi siempre con fondo de ciudad (lavaderos del Manzanares, Altos de Amaniel, la Moncloa, pradera de San Isidro, Puente de Toledo, Casa del Sordo, Puerte de los Franceses).

En estos paisajes, las figuras son casi siempre imperceptibles o no existen en contraste con el protagonismo y atención que se presta a la vegetación: encinas, pinos, chopos, eucaliptus, perfectamente diferenciados a pesar de su tratamiento en forma de manchas. Todo aparece bajo la luz pura y transparente del cielo madrileño que tan bien captó Veláz-

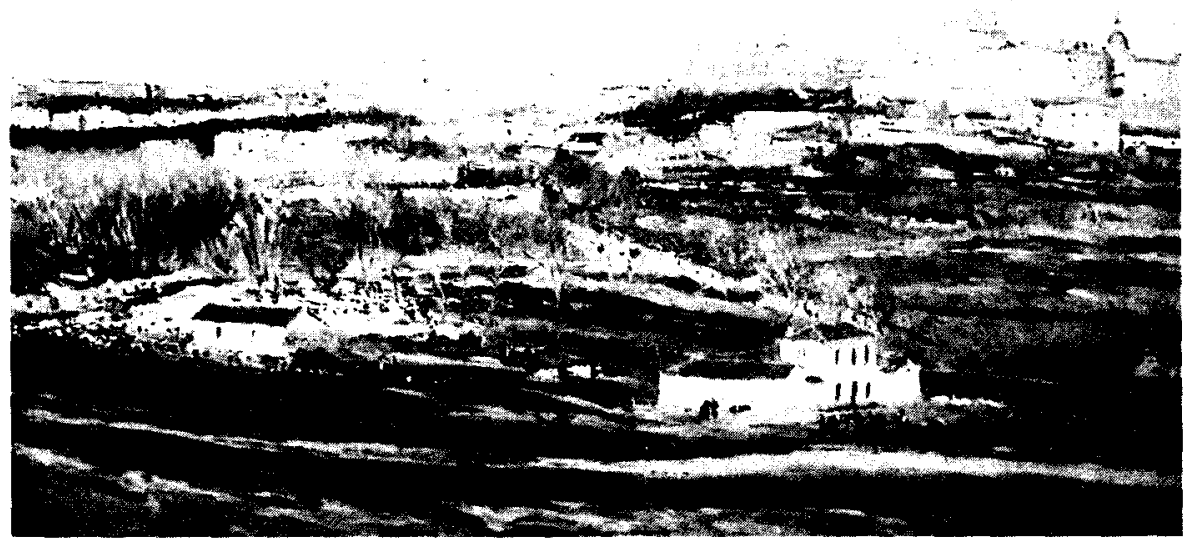

Fig. 8. Madrid, Pradera de San Isidro. Aureliano de Beruete. 
quez y que mereció loas de escritores y viajeros desde el Siglo de Oro hasta convertirse en uno de los estereotipos mentales de nuestra ciudad.

Vistas monumentales de edificios singulares de otras ciudades castellanas, sobre todo de Villaamil, son también expresión de la riqueza del patrimonio histórico artístico de Castilla y de su contribución a la imagen romántica de España. Por su número sobresalen las correspondientes a Burgos, Segovia, Alcalá de Henares, León y Salamanca.

Por su parte, las panorámicas de Beruete de Segovia, Ávila, Cuenca, destacando en la llanura solitaria y desolada de la meseta, forman parte de la imagen telúrica de España forjada por institucionistas y noventayochistas a partir de Castilla como tema fundamental de la cultura y del arte. Los paisajes castellanos de Regoyos, sobre todo los de Burgos y el paso de Pancorbo, complementan esa visión desde un vitalismo trágico y exacervado expresionismo que se relaciona con corrientes neorrománticas europeas y que también está presente en la España del 98.

En ese mismo contexto, destaca la intensidad con la que se percibe El Guadarrama. En el caso de Morera, a través de espacios de alta montaña, como los del Puerto de la Morcuera, Puerto de Canencia, la Fuenfria, Miraflores, Peñalara y Manzanares el Real, con atención a aspectos morfológicos y de vegetación. En el caso de Beruete, a través de panorámicas serranas desde la Moncloa, El Plantio o El Pardo, dentro de la tradición de los paisajes velazqueños y con una impronta romántica que expresa lo infinito mediante la lejania y la distancia.

Todos estos paisajes serranos responden al interés institucionista por el Guadarrama, favorecido por su proximidad a la capital, la contrucción del ferrocarril, y su temprano descubrimiento como motivo paisajístico por pintores románticos franceses y posteriores como Vicente Cuadrado y Martín Rico (PENA, C. 1983). A ello se añade la importancia creciente de los temas de alta montaña como subgénero de la pintura de paisajes desde la difusión de la obra "Viaje a los Alpes", publicada en 1779 por Horace Benedict de Saussure e ilustrada profusamente por Marc Theodore Burrit.

Por otro lado, también las ciudades andaluzas son identificadas con intensidad en los mapas mentales de España a partir de la obra de los pintores de paisaje. Las diferencias de percepción existentes entre unas a otras se justifican por la desigual riqueza de su patrimonio históricoartistico, la valoración de sus ambientes costumbristas, cargados de pintoresquismo, y su grado de relación con el tópico andaluz que acuñaron los viajeros románticos que recorrieron Andalucia en el siglo pasado (LoPEz ONTIVERos 1988).

El mayor número de vistas urbanas y de monumentos reproducidos pertenecen a Sevilla (Catedral, Torre del Oro, Giralda), Granada (Alham- 


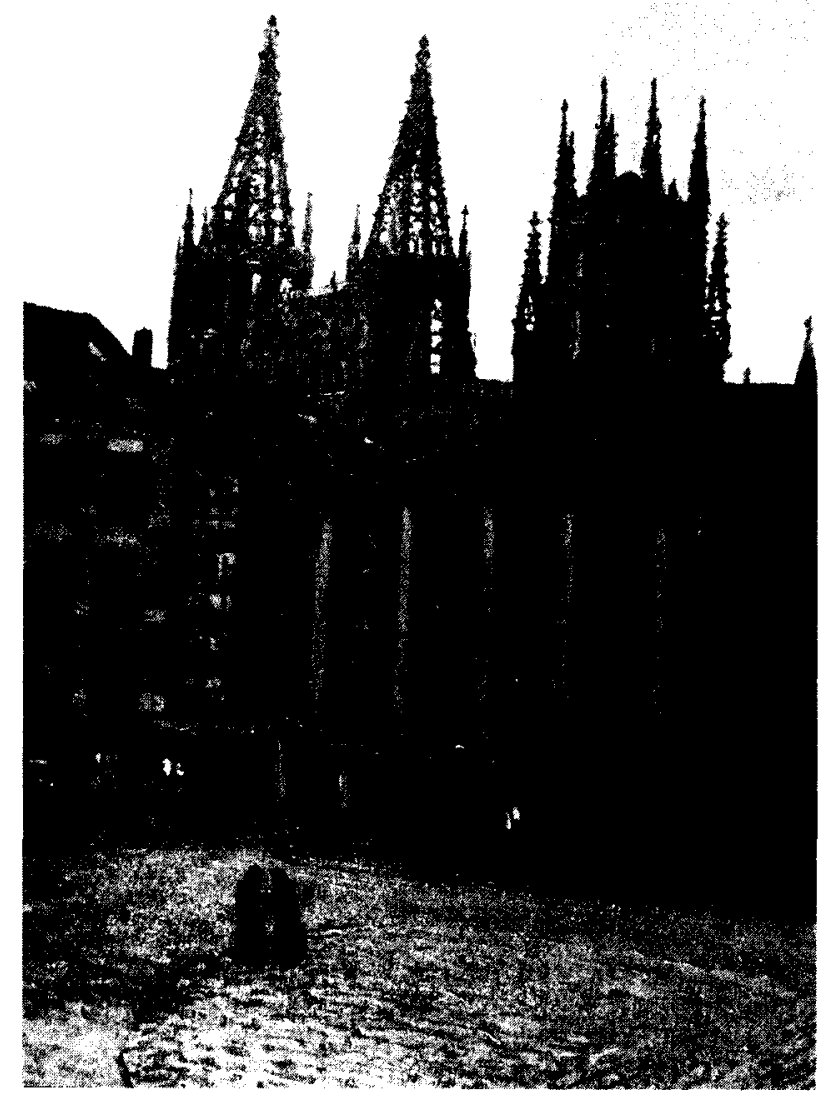

Fig. 9. Catedral de Burgos al atardecer. Dario de Regoyos.

bra, Generalife, Capilla Real), Córdoba (Mezquita, catedral) y Cádiz. Las tres primera ciudades son espacios privilegiados desde el punto de vista del componente oriental del mito andaluz, presente de forma obsesiva en viajeros como Gautier y Ford. Sin embargo, en el caso de Cádiz, su importancia se relaciona más con una geografia romántica que la mitifica por su significado mercantil, por su imagen de ciudad liberal y progresista, acrecentada durante su resistencia en la Guerra de Independencia, y por su papel en el nacimiento de la España liberal. Entre sus motivos más repetidos figuran vistas maritimas, puertas y murallas, calles y plazas populares que concentran la actividad ciudadana. 


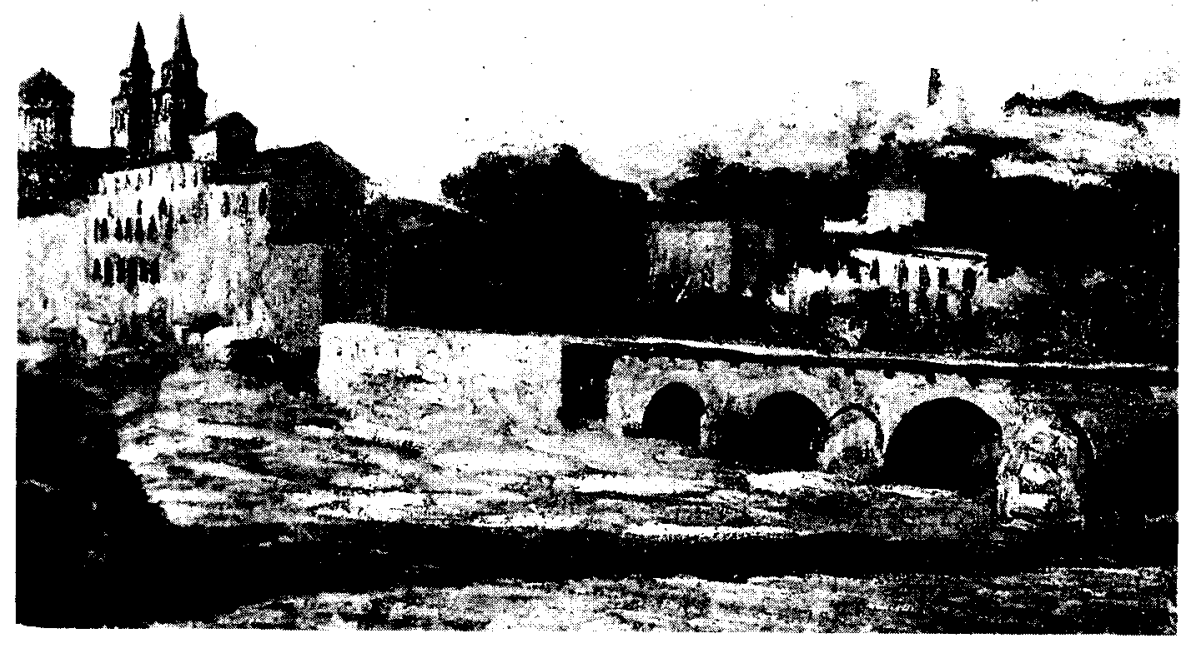

Fig. 10. Vista de Granada y puente sobre El Genil. Dario de Regoyos.

También destaca la localidad de Alcalá de Guadaira entre los paisajes andaluces, uno de los motivos favoritos de Pérez Villaamil, por su espectacularidad como pueblo fortaleza, con ruinas de fortificaciones musulmanas sobre un emplazamiento enhiesto y arriesgado sobre el río. Su pintoresquismo encaja bien con el gusto por lo vertical, lo agreste y lo sublime que lleva a escritores y pintores a preferir la montaña a la normalidad de la llanura.

En su conjunto, las localidades andaluzas son representadas, sobre todo por Villaamil, con un tratamiento escénico, con atención a monumentos y calles o plazas que recrean ensoñaciones poéticas y ofrecen escenas cotidianas o festivas mediante una multitud de personajes, con frecuencia pertenecientes a un terciario marginal.

Los paisajes de Dario de Regoyos, entre los que destacan los granadinos por su número, complementan la imagen andaluza desde presupuestos estéticos diferentes. La mayoria recogen espacios urbanos interiores e intimos, como el Arco de Doña Elvira, la Puerta de las Pasas, la Iglesia del Gran Capitán, la Cartuja o la Capilla de los Reyes Católicos, panorámicas amplias de la ciudad, con la presencia del río Genil, La Alhambra y Sierra Nevada, y temas de alta montaña.

Por último, los paisajes de la franja atlántica y cantábrica están igualmente bien representados en los artistas considerados y constituyen un 


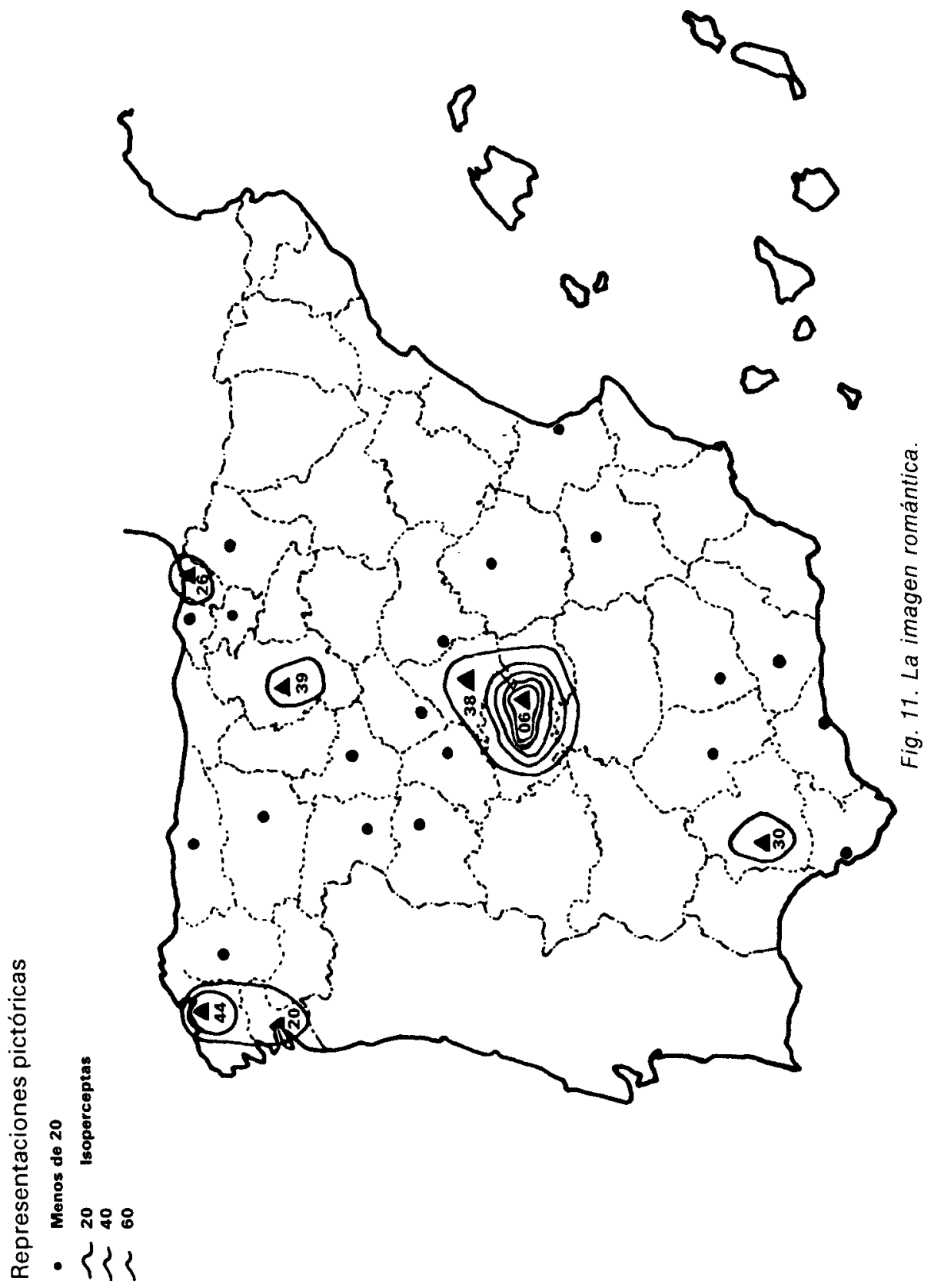




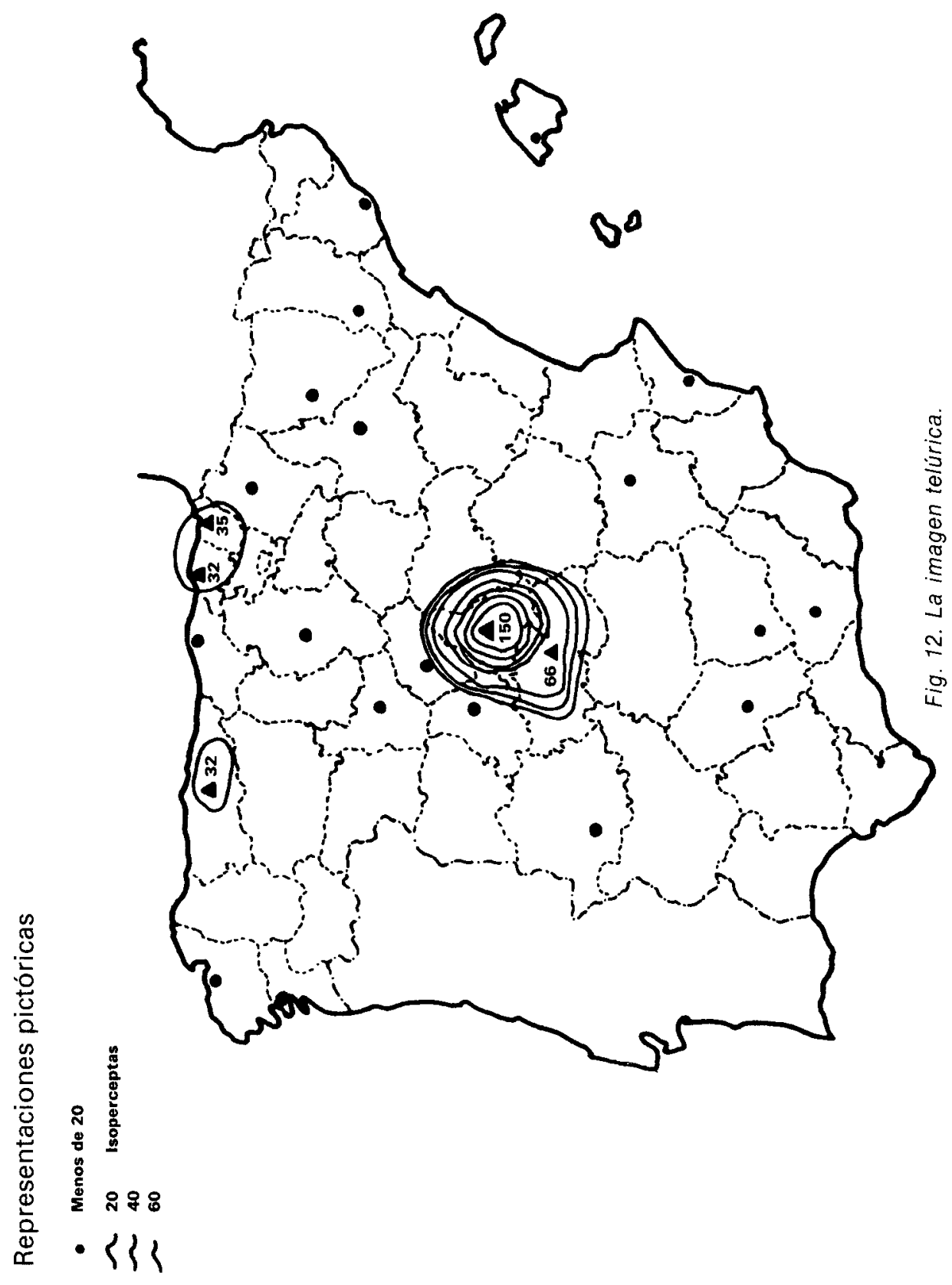




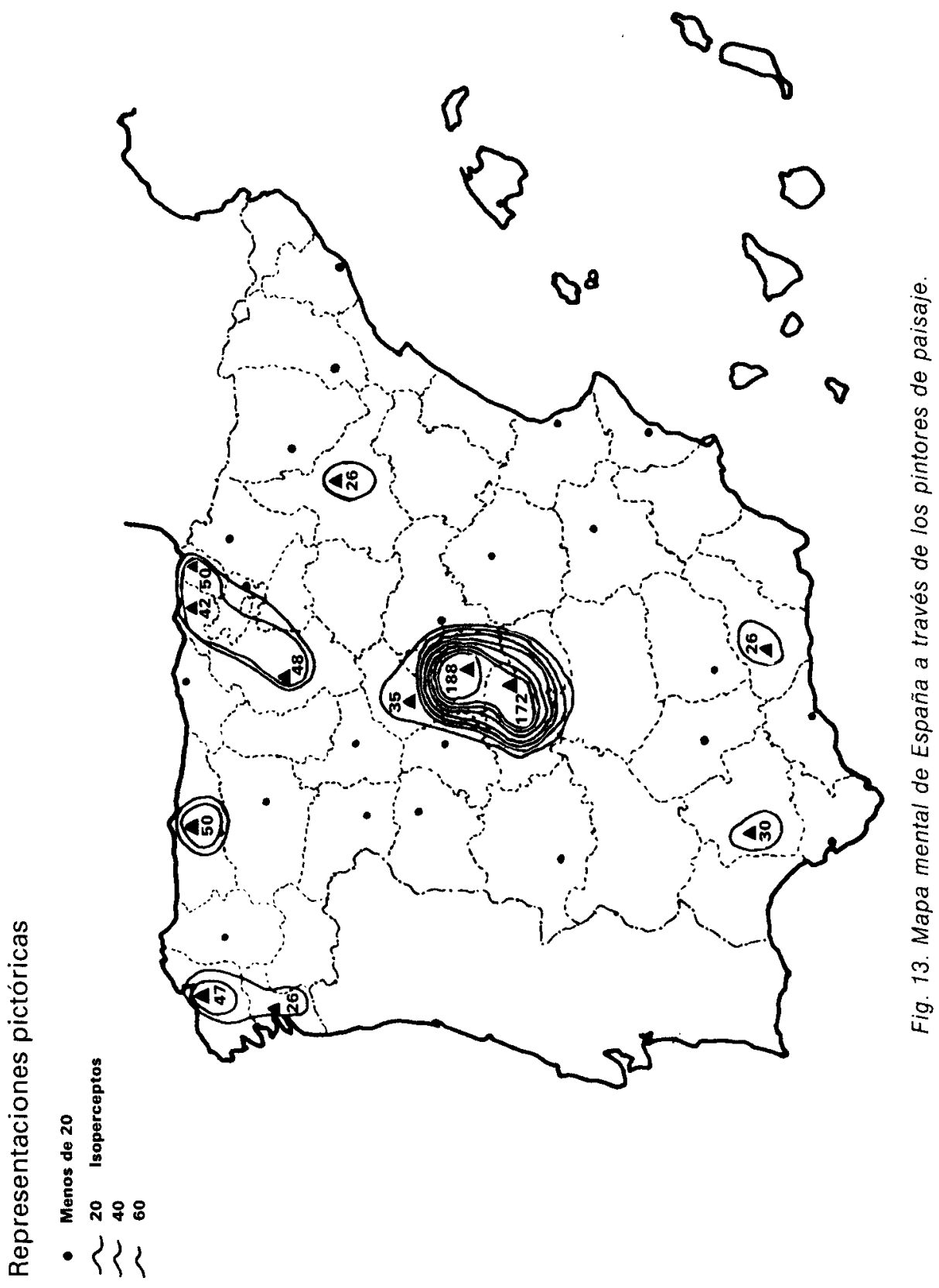


elemento fuerte de la imagen mental de España, a través de marinas, montañas, monumentos, fiestas, costumbres populares, ambientes pintorescos y escenarios urbanos que reflejan actividades productivas, transformación, cambio morfológico y social, en innovaciones tecnológicas de la primera industrialización. Sus escenarios más repetidos corresponden a las provincias de La Coruña (ría de Ares, Puentedeume, bahía de EI Ferrol, astilleros de La Graña, romerías de Cambre, iglesias de Betanzos, castillo de Andrade, etc.), Pontevedra (Puerto de Marin, Vistas de la playa y de la fábrica de salazón de Bueu, iglesias y conventos de la capital), Asturias (Oviedo, Covadonga, Picos de Europa), y localidades del País Vasco, entre las que destacan Bilbao y su industrializada ria, Azpeitia, Loyola, Lequeito y Tolosa.

La importancia númerica de las representaciones paisajísticas del Norte guarda relación con el interés de muchos de los pintores seleccionados por las bellezas artísticas y naturales de estas tierras, y por la existencia en algunos de ellos de especiales sentimientos de familiaridad y territorialidad con estos lugares por haber nacido o vivido en ellos. Asi, Jenaro Pérez Villaamil era natural de El Ferrol, Morera falleció en Algorta y Dario de Regoyos, nacido en Ribadesella, se identificó con los paisajes del Pais Vasco. A ello se añade el interés pictórico de estos paisajes por la calidad de sus luces y la vaporosidad de su atmósfera cargada de humedad, que prestan aire de ensueño romántico a la obra de arte, al tiempo que permiten expresar la experiencia y maestria de los pintores en el manejo del color, la luz y las formas.

Otros espacios de nuestra geografía han atraído menos a los grandes maestros del paisaje español y en consecuencia su incidencia en la imagen mental de España ha sido menos acusada. Existen zonas que constituyen verdaderos vacios en la geografia de las representaciones espaciales a partir de la visión de los pintores.

\section{BIBLIOGRAFIA}

ArIAs Angles, E. (1986): El paisajusta romántico Jenaro Pérez Villaamil. Madrid, CSIC

BAll Ly, A. (1978): La percepción del espacio urbano. Madrid, IEAL.

- (1985): “Distances et espaces: vingt ans de géographie des representations», L'Espace Géographique, $n .^{\circ} 3$, págs. 197-205.

- (1989): "L'imaginaire spatial. Plaidoyer pour la géographie des représentations", Espace-Temps, $\mathrm{n}^{\text {os }}$ 40-41, págs. 53-58.

Berque, A. (1982): Vivre l'espace au Japón. Paris, PUF.

Brown, J.; Kegan, R. L. et alt. (1982): El Greco de Toledo. Madrid, Alianza Editorial.

CAPEL, H. (1975); "L'image de la ville et le comportement spatial des citadins", L'espace géographique, 1, 73-80, pág. 74. 
Cossio (1908, 3 ed. 1965): El Greco. Madrid. Espasa Calpe.

GINER DE LOS RIOS. F. (1915): "Paisaje", Rev. La Lectura, vol. I, págs. 361-380.

GOODNEY, B. (1973): "Perception of environnement", Occasional Paper, n. ${ }^{\circ} 17$, University of Birmingham.

Hinterhauser, H. (1980): Fin de siglo. Figuras y mitos. Madrid, Ed. Taurus.

JACOBS, P. (1975): “Landscape image: current approaches to the visual analysis of the landscapes", Town Planning Review, vol. 46, n. ${ }^{\circ}$, pág. 127.

LEIGHLEY, J. (1937): "Somme comments on contemporary geographic method", Anna/s of the Association of American Geographers. Vol. 27, pág. 141.

Lopez Ontiveros, A. (1988): "El paisaje de Andalucia a través de los viajeros románticos: creación y pervivencia del mito andaluz desde una perspectiva geográfica", en Viajeros y paisajes, J. Gómez Mendoza y otros. Madrid, Alianza Editorial, págs. 31-65.

LYNCH, K. (1960): The image of the city. Cambridge, MIT Press.

Lleo Cañal, V. (1984): “Los viajes románticos", Estudios Turisticos, n. ${ }^{\circ} 83$, págs. 45-53.

Martinez de Pison, E. (1984): “Ciclos de viajes", Estudios Turisticos, n. ${ }^{\circ} 83$, págs. 5-30.

Pena, C. (1983): Pintura de paisaje e ideologia. La generación del 98. Madrid, Ed. Taurus.

Piveteau, J. L. (1989): "Les tableaux des peintres pour nôtre comprehension de l'espace». Représenter l'espace. Paris, Ed. Anthropos, págs. 109-122.

Pocock, D. C. D. (Ed. 1981): Humanistic Geography and Literature: Essays on the Experience of Place. London, Croom Helm.

REES, R. (1975): "The taste for mountain scenary", History Today, vol. XXV, may, pág. 305.

SimON, H. (1957): Models of man: social and rational. New York, Ed. Wiley.

TUAN, Y, Fu (1974): Topophilia: a study of environmental perception, attitudes and values. Ney Jersey, Prentice Hall, Englewood Cliffs.

- (1979): The Interpretation of ordinary landscapes: geographical essays. Oxford University Press.

YOUNGHUSBAND, F. (1920): “Natural beauty and geographical science”, Geographical Journal, vol, 56 , págs. $1-13$ 